\title{
Estimating leaf water content at the leaf scale in soybean inoculated with arbuscular mycorrhizal fungi from in situ spectral measurements
}

\author{
Weiping Kong ${ }^{1}$, Wenjiang Huang ${ }^{2 *}$, Xianfeng Zhou ${ }^{3}$, Hugh Mortimer ${ }^{4}$, \\ Lingling Ma ${ }^{1}$, Lingli Tang ${ }^{1}$, Chuanrong $\mathrm{Li}^{1}$ \\ (1. Key Laboratory of Quantitative Remote Sensing Information Technology, Aerospace Information Research Institute, Chinese Academy of \\ Sciences, Beijing 100094, China; 2. Key Laboratory of Digital Earth Science, Aerospace Information Research Institute, Chinese Academy \\ of Sciences, Beijing 100094, China; 3. College of Life Information Science and Instrument Engineering, Hangzhou Dianzi University, \\ Hangzhou 310018, China; 4. Rutherford Appleton Laboratory, Harwell Science and Innovations Campus, Oxfordshire, OX11 0QX, UK)
}

\begin{abstract}
Leaf water content (LWC) of crops is a suitable parameter for evaluation of plant water status and arbuscular mycorrhizal effect on the host plant under drought stress. Remote sensing technology provides an effective avenue to estimate LWC in crops. However, few LWC retrieval models have been developed specifically for the arbuscular mycorrhizal inoculated crops. In this study, soybean with inoculation and non-inoculation treatments were planted under the severe drought, moderate drought and normal irrigation levels. The LWC changes under different treatments at the $30^{\text {th }}, 45^{\text {th }}$ and $64^{\text {th }}$ day after the inoculation were investigated, and the spectral response characteristics of inoculated and non-inoculated soybean leaves under the three drought stresses were analyzed. Five types of spectral variables/indices including: raw spectral reflectance $(R)$, continuum-removed spectral reflectance $\left(R_{C}\right)$, difference vegetation index (DVI), normalized difference vegetation index (NDVI) and ratio vegetation index (RVI) were applied to determine the best estimator of LWC. The results indicate that LWC decreased as the aggravating of drought stress levels. However, LWC in inoculated leaves was higher than that in the counterparts under the same drought stress level, and the values of raw reflectance measured at inoculated leaves were lower than the non-inoculated leaves, especially around $1900 \mathrm{~nm}$ and $1410 \mathrm{~nm}$. These water spectral features were more evident in the corresponding continuum-removed spectral reflectance. The newly proposed $\mathrm{DVI}_{\mathrm{C}}(2280,1900)$ index, derived from the continuum-removed spectral reflectance at $2280 \mathrm{~nm}$ and the raw spectral reflectance at $1900 \mathrm{~nm}$ in DVI type of index, was the most robust for soybean LWC assessment, with $R^{2}$ value of $0.72(p<0.01)$ and root mean square error (RMSE) and mean absolute error (MAE) of $2.12 \%$ and $1.75 \%$, respectively. This study provides a means to monitor the mycorrhizal effect on drought-induced crops indirectly and non-destructively.
\end{abstract}

Keywords: leaf water content, remote sensing, arbuscular mycorrhizal fungi, drought, crops

DOI: $10.25165 /$ j.ijabe. 20191206.4950

Citation: Kong W P, Huang W J, Zhou X F, Mortimer H, Ma L L, Tang L L, et al. Estimating leaf water content at the leaf scale in soybean inoculated with arbuscular mycorrhizal fungi from in situ spectral measurements. Int J Agric \& Biol Eng, 2019; 12(6): 149-155.

\section{Introduction}

Drought stress is one of the main factors threating the agricultural development on the earth, as it limits crops growth and yield, especially in arid and semi-arid regions ${ }^{[1]}$. Soybean, a crop grown widely in China and very sensitive to soil moisture, is an important source of high quality protein and vegetable oils. However, about $45 \%$ land in China belongs to arid and semi-arid regions, and is expected to increase with climate change ${ }^{[2]}$, which

Received date: $2019-01-28 \quad$ Accepted date: $2019-09-05$

Biographies: Weiping Kong, $\mathrm{PhD}$, Assistant Researcher, research interest: the application of quantitative remote sensing in agriculture, Email: kongwp@radi.ac.cn; Xianfeng Zhou, PhD, research interest: agricultural remote sensing, Email: zhouxf@radi.ac.cn; Hugh Mortimer, PhD, Senior Engineer, research interest: hyspectral imager and agricultural remote sensing, Email: hugh.mortimer@stfc.ac.uk; Lingling Ma, PhD, Professor, research interest: quantitative remote sensing, Email: 1lma@aoe.ac.cn; Lingli Tang, Professor, research interest: quantitative remote sensing, Email: 1ltang@aoe.ac.cn; Chuanrong Li, Professor, research interest: quantitative remote sensing, Email: crli@aoe.ac.cn.

*Corresponding author: Wenjiang Huang, $\mathrm{PhD}$, Professor, research interest: the application of quantitative remote sensing in agriculture. Key Laboratory of Digital Earth Science, Institute of Remote Sensing and Digital Earth, Chinese Academy of Sciences, Beijing 100094, China. Tel: +86-10-82178169, Email: huangwj@radi.ac.cn. exposes soybean to drought stress. It is of utmost urgency to find a way to relief the influences of drought on its growth. Plants of $80 \%$ of plant families is known to form a symbiosis with the arbuscular mycorrhizal fungi ${ }^{[3]}$. Some studies have demonstrated that arbuscular mycorrhizal fungi associates with the plant roots in such relationship enhances the plant ability of water and nutrition uptakes $^{[1,4,5]}$, in particular when plants suffer from drought stress ${ }^{[6]}$, consequently, increasing drought resistance in plants and improve the water-use efficiency. Drought resistance in plants can occur via the maintenance of high internal water potentia ${ }^{[7]}$. Therefore, leaf water content (LWC) is a suitable parameter for evaluation of plant water status and mycorrhizal effect under drought stress.

Remote sensing technology provides an effective and non-destructive way to acquire spatial and time-critical information on crop biochemical parameters, such as leaf area index, leaf pigment content, leaf nitrogen content etc. ${ }^{[8-11]}$. The strong absorption of leaf water in short-wave infrared (SWIR) region $(1300-2500 \mathrm{~nm})$ and the weak absorption in near infrared (NIR) region $(750-1300 \mathrm{~nm})$ make it possible to estimate LWC of crops from remote sensing data $^{[12,13]}$, and then offers a new insight to indirectly and non-destructively evaluate the mycorrhizal effect.

In recent years, substantial efforts are expanded to study the relationship between spectral reflectance in the 400-2500 nm region and water content in leaves through vegetation indices (VIs) 
and machine learning regression analysis, etc. ${ }^{[14-16]}$. A common approach of estimating LWC has been the reliance on VIs, which combines the raw spectral reflectance at NIR and SWIR regions through some linear or nonlinear mathematical formulas. A number of water indices have been developed in previous studies. Specifically, ratio vegetation index (RVI), normalized difference vegetation index (NDVI) and difference vegetation index (DVI) are three types of water indices, widely used not only based on ground based but also airborne or satellite remote sensing data, such as water index ${ }^{[17]}$, normalized difference water index ${ }^{[18]}$, double differences water index ${ }^{[19]}$. In addition, Gaussian process regression (GPR) have been developed based on the theory of Bayesian and statistical learning ${ }^{[20]}$, which estimates a variable of interest using a training database of biochemical parameter (e.g. LWC) and spectral data pairs. Studies indicated that GPR has provided the solutions for the high-dimensional, small-sampled and non-linear regression issues, and current vegetation biochemical parameter products are produced with this method ${ }^{[21-23]}$. The continuum removal processing ${ }^{[24]}$ has been used as a spectral tool to suppress other factors, consequently, enhancing the spectral absorption features of the interests ${ }^{[25]}$. Thus, to combine the information on the raw and continue-removed spectral reflectance might be an effective way to improve the accuracy of LWC estimation. However, it has been gained less attention in the present studies.

Previous studies have concentrated on the effect of arbuscular mycorrhizal inoculation on crop LWC and crop LWC estimation from remote sensing data ${ }^{[6,26-28]}$. However, few studies have been carried out to study the spectral response characteristics of the arbuscular mycorrhizal inoculated soybean under drought stress, and no optical LWC retrieval models have yet been developed specifically for the inoculated soybean. The objectives of this study were: 1) to compare the LWC of inoculated and non-inoculated soybean under drought stress during different inoculation periods; 2 ) to investigate the response characteristics of the raw and continuum-removed spectra of inoculated and non-inoculated soybean at the water absorption wavebands; 3) to correlate the LWC with the raw and continuum-removed spectral reflectance, aiming to explore the most sensitive bands to estimate LWC; 4) to compare the performances of the newly built LWC retrieval models combining the raw and continuum-removed spectral information with those only including one sort of the spectral information, and to determine the optimal LWC retrieval model for the inoculated and non-inoculated soybean.

\section{Materials and methods}

\subsection{Study site and experimental design}

The experiment was carried out in the microbial remediation greenhouse at China University of Mining and Technology (Beijing) $\left(116^{\circ} 21.3^{\prime} \mathrm{E}, 40^{\circ} 00^{\prime} \mathrm{N}\right)$ in 2013 . A cultivar of soybean (Zhonghuang 35, provided by Chinese Academy of Agricultural Sciences) was selected for this study. The tested strains were arbuscular mycorrhizal Glomus intraradices (G.i.), which was provided by Plant Nutrition and Resources Research Institute, Beijing Academy of Agriculture and Forestry Sciences. The experimental soil was sandy soil, with nutrient content about $150 \mathrm{mg} / \mathrm{kg}$ of potassium, $10 \mathrm{mg} / \mathrm{kg}$ of phosphorus, $100 \mathrm{mg} / \mathrm{kg}$ of nitrogen before sowing, and the maximum water holding capacity of $25.7 \%$. $\quad 4.8 \mathrm{~kg}$ per pot of sandy soil was filled into the pots ( $24 \mathrm{~cm}$ (top diameter) $\times 15 \mathrm{~cm}$ (bottom diameter) $\times 18 \mathrm{~cm}$ (height)) after autoclaving and drying. 5 soybean seeds were planted in each pot, 2 healthy and uniformed seedlings were remained per pot after the fourth week of emergence, and were subjected to drought stress treatments.

A series of drought stress levels were set, i.e. severe drought (W1), moderate drought (W2) and normal irrigation (W3), with the maximum water holding capacity of $35 \%, 55 \%$ and $75 \%$, respectively. For each drought stress level, there were inoculated $(+\mathrm{M})$ and non-inoculated (CK) treatments. $100 \mathrm{~g}$ of G.i. inoculants per pot were inoculated in $+\mathrm{M}$ treatment, accordingly, $100 \mathrm{~g}$ normal sandy soil (about 95\% sand and 5\% clay) per pot were added in CK treatment. Each treatment had 4 repeats and was harvested 3 times, with a total of 72 pots. All pots were randomly placed in the greenhouse.

Spectral reflectance measurement and LWC determination were carried out during different inoculation periods: Day 30 (i.e. the tenth day after suffering from drought stress), Day 45 and Day 64 after the inoculation.

\subsection{Spectral reflectance measurement}

An ASD FieldSpec 3 spectrometer (Analytical Spectral Devices, Boulder, CO), with a $25^{\circ}$ field-of-view fiber optics, was used to measure leaf spectral reflectance of soybean. It records spectral radiance with a sampling interval of $1.4 \mathrm{~nm}$ and a resolution of $3.0 \mathrm{~nm}$ between $400 \mathrm{~nm}$ and $1050 \mathrm{~nm}$, and a sampling interval of $2.0 \mathrm{~nm}$ and a resolution of $10.0 \mathrm{~nm}$ between $1000 \mathrm{~nm}$ and $2500 \mathrm{~nm}$. The measurements were conducted in a dark room at the room temperature. Leaf illumination was provided by a halogen lamp matched with the spectrometer, the measurement height above the leaves was $10 \mathrm{~cm}$. Each spectral measurement was preceded by a white reference measurement using a white Spectralon ${ }^{\circledR}$ (Labsphere, Inc. New Hampshire, USA) reference panel. Two leaves were selected and cut from the top, middle and lower layers, respectively, from each pot, and were measured from four angles by rotating $90^{\circ}$, ten scans were conducted per angle, with forty scans in total per leaf. All scans of six leaves were averaged to obtain spectral reflectance for each soybean pot.

\subsection{Leaf water content measurement}

After spectral measurement, leaves were cut and weighed immediately to obtain the fresh weight (FW) using analytical balance. Then they were dried at $105^{\circ} \mathrm{C}$ for $30 \mathrm{~min}$ in an oven and subsequently dried at $80^{\circ} \mathrm{C}$ until constant weight, dry weight (DW) of leaves were recorded after weighing. Leaf water content (LWC) $(\%)$ was calculated as:

$$
\text { LWC }(\%)=\frac{F W-D W}{F W} \times 100 \%
$$

\subsection{Continuum removal processing of spectra}

The continuum removal processing was accomplished by rationing the raw spectral reflectance with a continuum line of convex hull connecting the high points on the left and right sides of a spectrum (Figure 1). The continuum-removed spectral reflectance $\left(R_{C}(\lambda)\right)$ was calculated as ${ }^{[29]}$ :

$$
R_{C}(\lambda)=\frac{R(\lambda)}{R_{L}(\lambda)}
$$

where, $R(\lambda)$ is the raw spectral reflectance; $R_{L}(\lambda)$ is the corresponding reflectance of the continuum line.

\subsection{The construction of vegetation indices}

DVI, NDVI and RVI are three types of VIs, which were successfully used for the remote estimation of vegetation biochemical parameters in numerous published literatures ${ }^{[11,30-32]}$. In this study, we explored the three types of VIs to combine the information on the raw spectral reflectance $(R(\lambda))$ with the 
continuum-removed spectral reflectance $\left(R_{C}(\lambda)\right)$ of soybean leaves, and thus the new VIs were formulated by Equation (3)-(5), referred to as the $\operatorname{DVI}_{\mathrm{C}}(\lambda 1, \lambda 2), \operatorname{NDVI}_{\mathrm{C}}(\lambda 1, \lambda 2)$ and $\operatorname{RVI}_{\mathrm{C}}(\lambda 1, \lambda 2)$.

$$
\begin{gathered}
\operatorname{DVI}_{\mathrm{C}}(\lambda 1, \lambda 2)=R_{C}(\lambda 1)-R(\lambda 2) \\
\operatorname{NDVI}_{\mathrm{C}}(\lambda 1, \lambda 2)=\frac{R_{C}(\lambda 1)-R(\lambda 2)}{R_{C}(\lambda 1)+R(\lambda 2)} \\
\operatorname{RVI}_{C}(\lambda 1, \lambda 2)=\frac{R_{C}(\lambda 1)}{R(\lambda 2)}
\end{gathered}
$$

where, $R_{C}(\lambda 1)$ is the value of continuum-removed spectral reflectance at wavelength $\lambda 1 ; R(\lambda 2)$ is the value of raw spectral reflectance at wavelength $\lambda 2$.

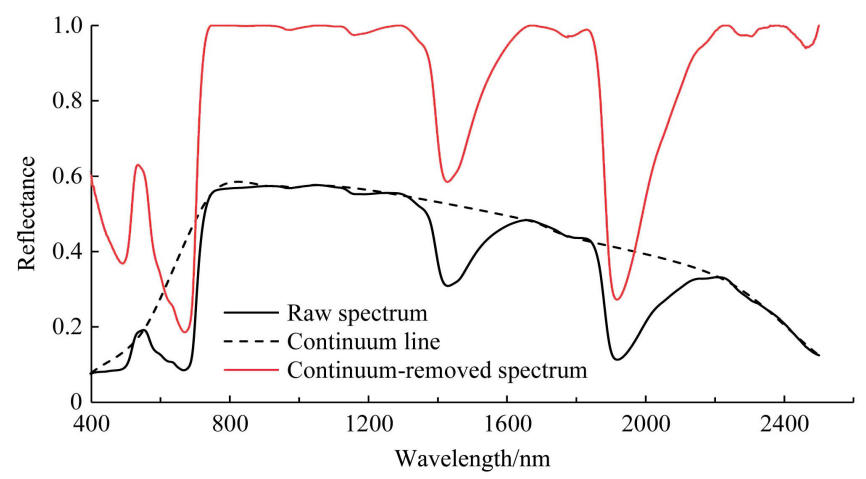

Figure 1 Continuum removal process of a spectrum

\subsection{Model calibration and validation scheme}

Altogether 66 datasets were acquired after removing the outlier of spectral reflectance or LWC of inoculated and non-inoculated soybean. 46 datasets were used to build the retrieval models, and the remaining 20 dataset were used to validate LWC prediction. Methods of linear regression and the GPR were applied for model calibration. The former one was used to build the model between LWC and VIs, the latter one was used to establish the models between LWC and the raw/continuum-removed spectral reflectance at a range of sensitive wavebands. To compare the performance of different VIs/sensitive spectral reflectance, we calculated coefficients of determination $\left(R^{2}\right), p$ value, root mean square error (RMSE) and mean absolute error (MAE). RMSE and MAE were computed as follows:

$$
\begin{gathered}
\text { RMSE }=\sqrt{\sum_{i=1}^{n}\left(\hat{y}_{i}-y_{i}\right)^{2} / n} \\
\text { MAE }=\frac{1}{n} \sum_{i=1}^{n}\left|\hat{y}_{i}-y_{i}\right|
\end{gathered}
$$

\section{Results and discussion}

\subsection{The effects of inoculation on leaf water content of soybean under drought stresses}

The changes of LWC of soybean under different treatments at three inoculation periods are shown in Table 1. For all treatments, LWC decreased firstly and then increased as time went on. The leaves of soybean had lower LWC with the aggravating of drought stress levels at Day 30, indicating that drought resulted in the drop of water in leaves entirely. However, at Day $45,+\mathrm{M}$ soybean treatments yielded an increase in LWC by $3.4 \%, 1.8 \%, 3.9 \%$ under the W1, W2 and W3 levels, respectively, as compared to the corresponding counterparts of CK treatments, which in accordance with the finding of Aliasgharzad et al. ${ }^{[5]}$ This result indicated that arbuscular mycorrhizal inoculation can alleviate the influence of drought on LWC of soybean. It may mainly attribute to the mycorrhizal effect on the host plants. The roots of plants that were inoculated would gradually form the symbionts with arbuscular mycorrhizal fungi after suffering from drought stress. The shape of ectomycorrhizal symbionts would be changed to protect host plants against drought damage, consequently, improving the uptakes of water from the soil ${ }^{[6]}$. After $64 \mathrm{~d}$ of the inoculation, for the W2 treatment, LWC of $+\mathrm{M}$ soybean was still higher than that of CK soybean. But under the other two drought stress levels, there was the opposite of the occurrence, because this period was the end of soybean growth stage, the $+\mathrm{M}$ plants had relatively larger leaf area compared to the CK plants, which increased the transpiration and accordingly led to the low LWC.

Table 1 LWC of soybean (\%) under different treatments at three inoculation periods

\begin{tabular}{cccccccc}
\hline \multirow{2}{*}{ Treatments } & \multicolumn{2}{c}{ Day 30 } & \multicolumn{2}{c}{ Day 45 } & \multicolumn{2}{c}{ Day 64 } \\
\cline { 2 - 7 } & $+\mathrm{M}$ & $\mathrm{CK}$ & & $+\mathrm{M}$ & $\mathrm{CK}$ & $+\mathrm{M}$ & CK \\
\hline W1 & $72.15 \mathrm{a}$ & $74.41 \mathrm{a}$ & $67.87 \mathrm{a}$ & $65.61 \mathrm{a}$ & $71.30 \mathrm{c}$ & $72.39 \mathrm{bc}$ \\
W2 & $75.45 \mathrm{a}$ & $74.75 \mathrm{a}$ & $68.82 \mathrm{a}$ & $67.63 \mathrm{a}$ & $73.35 \mathrm{ab}$ & $72.94 \mathrm{bc}$ \\
W3 & $77.80 \mathrm{a}$ & $75.10 \mathrm{a}$ & $69.81 \mathrm{a}$ & $67.18 \mathrm{a}$ & $71.42 \mathrm{bc}$ & $75.08 \mathrm{a}$ \\
\hline
\end{tabular}

Note: Differences in LWC at the same inoculation period among the treatments were tested by the least significant difference (LSD) method. Different letters indicate significant difference $(p<0.05)$; W1, W2 and W3 indicate severe drought, moderate drought and normal irrigation, respectively; $+\mathrm{M}$ and $\mathrm{CK}$ indicate inoculation and non-inoculation treatments, respectively.

3.2 The characteristics of the raw spectra and continuumremoved spectra of inoculated and non-inoculated soybean under drought stresses

Spectral reflectance measured at Day 45 after the inoculation was chosen as an example to demonstrate its response characteristics under different treatments and its relationship with LWC. As the reflectance values in the near infrared (NIR) and short-wave infrared (SWIR) bands were mainly determined by the amount of water in leaves ${ }^{[31]}$, we then analyzed the spectral response characteristics from $750 \mathrm{~nm}$ to $2500 \mathrm{~nm}$ in more detail. As shown in Figure 2a, spectral reflectance of all treatments presented two obvious spectral absorption features around $1410 \mathrm{~nm}$ and $1900 \mathrm{~nm}$ wavebands. This is because the H-O bond of water molecules in leaves interacts with light quantum, leading to the strong absorption characteristics and the lower reflectance values at these wavebands. At Day 45, spectral reflectance of $+\mathrm{M}$ and $\mathrm{CK}$ soybean leaves was on the rise with the increasing of drought stress levels, with the large values of the W1 level and the small values of the W3 level, indicating that LWC was negatively correlated to reflectance values, especially around $1410 \mathrm{~nm}$ and $1900 \mathrm{~nm}$. However, under the same drought stress, reflectance values of $+\mathrm{M}$ treatment were lower than that of $\mathrm{CK}$ treatment, highlighting that LWC of the former were higher than the latter. Different treatments showed the same pattern but different reflectance values. For example, around $1410 \mathrm{~nm}$, the $\mathrm{W} 3+\mathrm{M}$ values were significantly lower than the others, while the W1CK had the highest reflectance values, the values between the $\mathrm{W} 1+\mathrm{M}$ and the W2CK were comparative. This indicated that at Day 45, the $\mathrm{W} 3+\mathrm{M}$ and the $\mathrm{W} 1 \mathrm{CK}$ treatments had the largest and smallest LWC respectively, and the $\mathrm{W} 1+\mathrm{M}$ and the $\mathrm{W} 2 \mathrm{CK}$ treatments had almost the same LWC, which was consistent with the LWC data measured in the lab.

We performed the continuum removal processing on the raw spectra, the result is shown in Figure $2 b$. From Figure $2 b$, the spectral reflectance differences at some absorption channels had been obviously highlighted, e.g. the absorption bands of leaf water 
(i.e. around $1410 \mathrm{~nm}$ and $1900 \mathrm{~nm}$ ), whereas the differences at some reflection channels had been suppressed, compared to the raw spectral reflectance (Figure 2a). At Day 45, the spectral absorption depths of different treatments were different around $1900 \mathrm{~nm}$ and $1410 \mathrm{~nm}$. In general, W1CK produced the smallest absorption depth; under the same drought stress level, the absorption depths of $+\mathrm{M}$ treatments were larger than those of $\mathrm{CK}$ treatments.
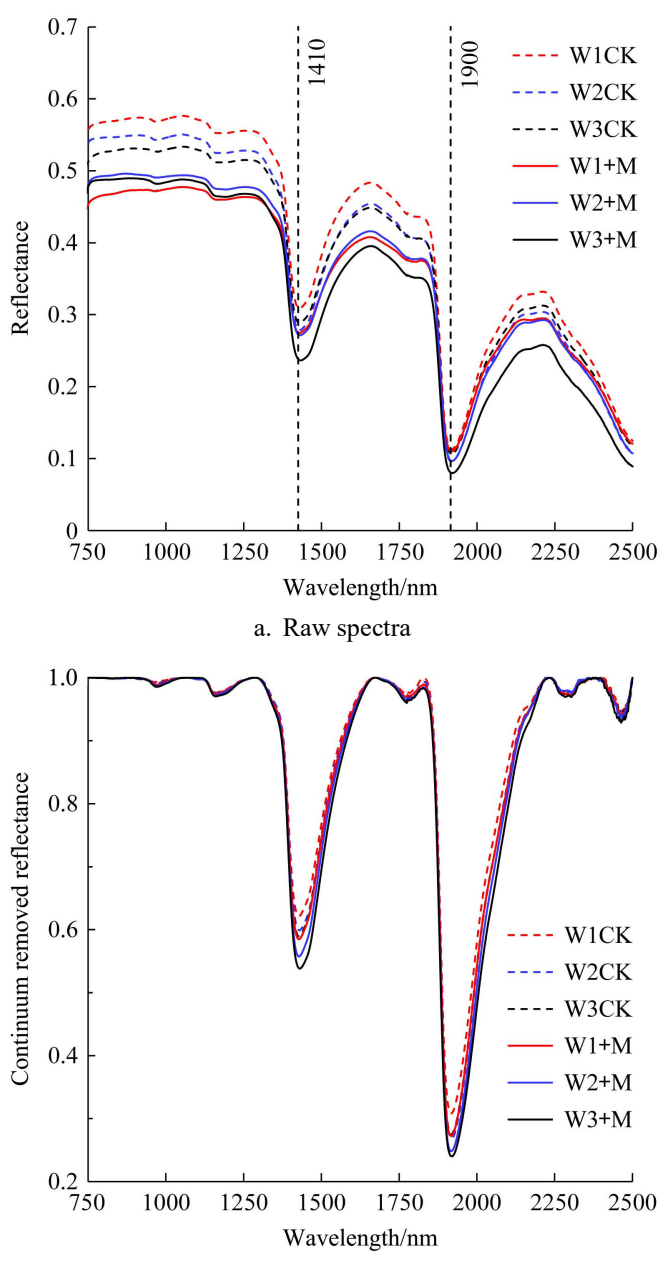

b. Continuum- removed spectra

Note: W1, W2 and W3 represent severe, moderate drought and normal irrigation, respectively; $+\mathrm{M}$ and $\mathrm{CK}$ represent inoculation and non-inoculation, respectively. $\mathrm{W} 1 \mathrm{CK}$ indicates the treatment with severe drought and non-inoculation, $\mathrm{W} 1+\mathrm{M}$ indicates the treatment with severe drought and inoculation, etc.

Figure 2 Reflectance of the raw spectra (a) and the continuumremoved spectra (b) under different treatments at Day 45

\subsection{Correlation between leaf water content and the raw spectral reflectance}

The correlation between the spectral reflectance and LWC of inoculated and non-inoculated soybean under drought stresses can be evaluated by correlation coefficient $(r)$. The correlation between the raw spectral reflectance and LWC at 750-2500 nm was analyzed (Figure 3). Reflectance at 1870-1970 nm and 1400$1460 \mathrm{~nm}$ regions negatively correlated well with LWC, with the highest $r$ values of -0.69 at $1900 \mathrm{~nm}$ and -0.52 at $1410 \mathrm{~nm}$, respectively. These bands can be regarded as the sensitive wavebands to assess the changes of LWC, and the spectral reflectance values at $1900 \mathrm{~nm}$ and $1410 \mathrm{~nm}$ were used to construct VIs (i.e. $R(\lambda 2)$ in the VIs).

3.4 Correlation between leaf water content and the continuum-removed spectral reflectance

Spectral absorption features of the interest targets (e.g. LWC) can be amplified through the continuum removal processing ${ }^{[24,25]}$. The correlation between the continuum-removed spectral reflectance and LWC is shown in Figure 4. Four positive/ negative correlation peaks with high $r$ values were acquired, i.e. the spectral ranges of 2250-2330 nm, 1850-1890 nm, 1690-1730 nm and $1125-1175 \mathrm{~nm}$. Thus the continuum-removed reflectance at these bands was used for the LWC retrieval.

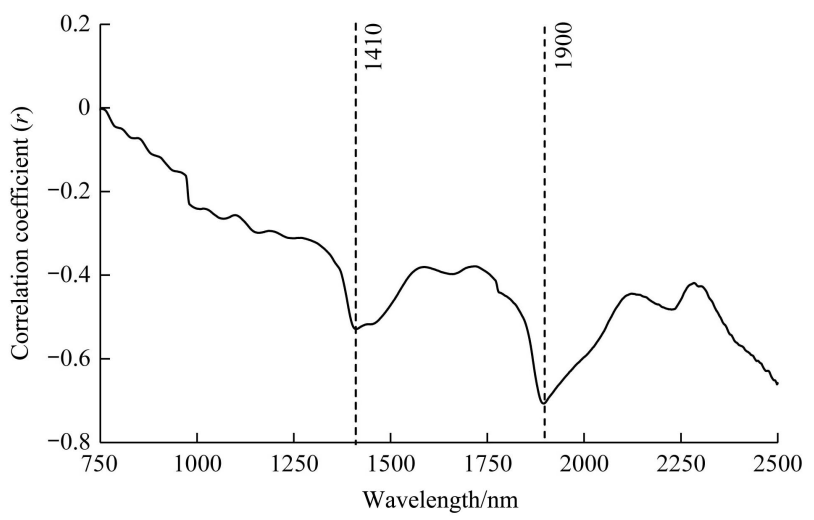

Figure 3 The correlation between the raw spectral reflectance and LWC of soybean

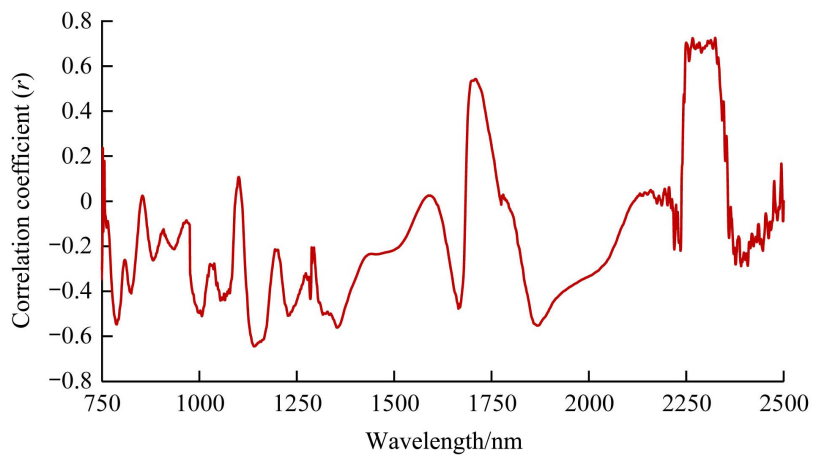

Figure 4 Correlation between the continuum-removed reflectance and LWC of soybean

3.5 The selection of continuum-removed spectral bands for vegetation indices

The $\mathrm{DVI}_{\mathrm{C}}, \mathrm{NDVI}_{\mathrm{C}}$ and $\mathrm{RVI}_{\mathrm{C}}$ proposed in this study, were composed by two variables, $R_{C}(\lambda 1)$ and $R(\lambda 2)$. It should be noted that $R_{C}(\lambda 1)$ indicates the continuum-removed spectral reflectance at $\lambda 1 \mathrm{~nm}, R(\lambda 2)$ indicates the raw spectral reflectance at $\lambda 2 \mathrm{~nm}$, and $\lambda 2$ was determined to be $1900 \mathrm{~nm}$ or $1410 \mathrm{~nm}$ in section 3.2. To find the best $\lambda 1$ for VIs which was sensitive to LWC, we calculated the spectral reflectance of every band from $400-2500 \mathrm{~nm}$ to combined with $R(1900)$ and $R(1410)$ in $\mathrm{DVI}_{\mathrm{C}}$, $\mathrm{NDVI}_{\mathrm{C}}$ and $\mathrm{RVI}_{\mathrm{C}}$ types of indices, respectively, and then studied the VIs behavior of coefficient of determination $\left(R^{2}\right)$, referred as $R^{2}\{$ VIs vs. LWC $\}$, the results are shown in Figure 5. Compared with $V I_{C}(\lambda 1,1900)$, three types of $V I_{C}(\lambda 1,1410)$ yielded relatively lower $R^{2}$ at all bands from $400 \mathrm{~nm}$ to $2500 \mathrm{~nm}$, this may because the spectral reflectance at $1410 \mathrm{~nm}$ had weaker correlation with LWC than that at $1900 \mathrm{~nm}$ (Figure 3). For $V I_{C}(\lambda 1,1900)$ and $V I_{C}(\lambda 1,1410), R^{2}$ values were small when $\lambda 1$ at the visible to near infrared region (400-1300 nm). However, when $\lambda 1$ at the SWIR region $(1300-2500 \mathrm{~nm})$, the $R^{2}$ tended to increase, except for around 1800-2000 nm. It was worth noting that there appeared to be two peaks achieving higher $R^{2}$ values for all six VIs, with the maximum were all around $2280 \mathrm{~nm}$, indicating that the $V I_{C}(\lambda 1,1900)$ and $V I_{C}(\lambda 1,1410)$ were more 
sensitive to LWC when $\lambda 1$ was $2280 \mathrm{~nm}$ in this study. Finally, the $R_{C}(2280)$ and $R(1900), R(1410)$ were selected for the VIs integrating information on the continuum-removed spectra and the raw spectra to quantify LWC of soybean in this study, they were summarized in Table 2 .

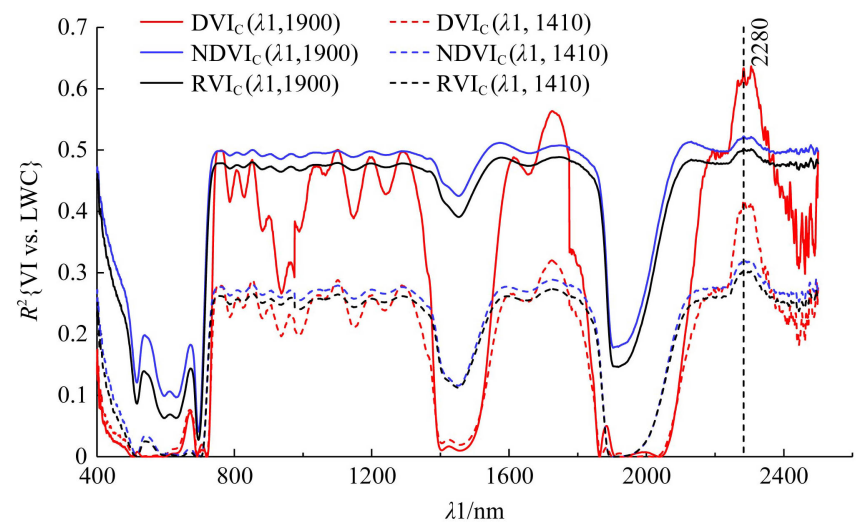

Figure 5 The $R^{2}$ of relationship between $\operatorname{LWC}$ and $\operatorname{VI}_{\mathrm{C}}(\lambda 1,1900)$ and $\operatorname{VI}_{C}(\lambda 1,1410)$ when continuum-removed spectral band $\lambda 1$ changed from $400-2500 \mathrm{~nm} . \mathrm{VI}_{\mathrm{C}}$ includes $\mathrm{DVI}_{\mathrm{C}}, \mathrm{NDVI}_{\mathrm{C}}$ and $\mathrm{RVI}_{\mathrm{C}}$
3.6 Retrieval models for leaf water content and model validations

3.6.1 Retrieval models for leaf water content

Given that LWC of soybean correlated well with the raw spectral reflectance at $1870-1970 \mathrm{~nm}$ and $1400-1460 \mathrm{~nm}$ (referred to as $\mathrm{R}_{1870-1970}$ and $\mathrm{R}_{1400-1460}$ ), as well as the continuum-removed spectral reflectance at $2250-2330 \mathrm{~nm}, 1850-1890 \mathrm{~nm}, 1690$ $1730 \mathrm{~nm}$ and 1125-1175 $\mathrm{nm}$ (referred to as $\mathrm{R}_{\mathrm{C} 2250-2330}, \mathrm{R}_{\mathrm{C} 1850-1890}$, $\mathrm{R}_{\mathrm{C} 1690-1730}$ and $\mathrm{R}_{\mathrm{C} 1125-1175)}$, we developed the LWC retrieval models using the above spectral variables, by the method of GPR. The $R^{2}$ RMSE and $\mathrm{p}$ values of retrieval models are summarized in Table 3. In addition, the linear retrieval models between LWC vs. the six newly proposed $V I_{C}(\lambda 1, \lambda 2)$ are presented in Figure 6 . For all the spectral variables/indices, the highest coefficient $\left(R^{2}=0.72, p<0.01\right)$ for LWC estimation was achieved using a model built by the $\operatorname{DVI}_{\mathrm{C}}(2280,1900)$ (Figure 6d), followed by the model using the $\mathrm{R}_{\mathrm{C} 2250-2330}\left(R^{2}=0.66, p<0.01\right)$ and $\mathrm{R}_{1870-1970}\left(R^{2}=0.64, p<0.01\right)$ (Table 3). These results indicated that the DVI type index combining the raw and continuum-removed spectral information will obtain a better accuracy in LWC retrieval than that containing only one sort of information on the continuum-removed or raw spectra, for the arbuscular mycorrhizal inoculated soybean leaves under drought stresses.

Table 2 Summarization of vegetation indices used in the study

\begin{tabular}{ccc}
\hline VIs & Formula & \\
\hline $\operatorname{DVI}_{\mathrm{C}}(2280,1900)$ & $R_{C}(2280)-R(1900)$ & Description \\
$\mathrm{NDVI}_{\mathrm{C}}(2280,1900)$ & $\frac{R_{C}(2280)-R(1900)}{R_{C}(2280)+R(1900)}$ & Normalization between the continuum-removed reflectance at $2280 \mathrm{~nm}$ and the raw reflectance at $1900 \mathrm{~nm}$. \\
$\mathrm{RVI}_{C}(2280,1900)$ & $\frac{R_{C}(2280)}{R(1900)}$ & Ratio of the continuum-removed reflectance at $2280 \mathrm{~nm}$ to the raw reflectance at $1900 \mathrm{~nm}$. \\
$\mathrm{DVI}_{\mathrm{C}}(2280,1410)$ & $\frac{R_{C}(2280)-R(1410)}{R_{C}(2280)-R(1410)}$ & Difference between the continuum-removed reflectance at $2280 \mathrm{~nm}$ and the raw reflectance at $1410 \mathrm{~nm}$. \\
$\mathrm{NDVI}_{\mathrm{C}}(2280,1410)$ & $\frac{R_{C}(2280)}{R(1410)}$ & Normalization between the continuum-removed reflectance at $2280 \mathrm{~nm}$ and the raw reflectance at $1410 \mathrm{~nm}$. \\
$\mathrm{RVI}_{C}(2280,1410)$ &
\end{tabular}

Table 3 The $\boldsymbol{R}^{2}$ and RMSE of retrieval models between LWC vs. spectral variables using GPR ( $\left.n=46\right)$

\begin{tabular}{ccc}
\hline Spectral variables & Determination of coefficient $/ R^{2}$ & $p$ value \\
\hline $\mathrm{R}_{1870-1970}$ & 0.65 & 2.36 \\
$\mathrm{R}_{1400-1460}$ & 0.56 & 2.51 \\
$\mathrm{R}_{\mathrm{C} 2250-2330}$ & 0.66 & 2.15 \\
$\mathrm{R}_{\mathrm{C} 1850-1890}$ & 0.49 & 2.42 \\
$\mathrm{R}_{\mathrm{C} 1690-1730}$ & 0.57 & 2.37 \\
$\mathrm{R}_{\mathrm{C} 1125-1175}$ & 0.47 & 2.56 \\
\hline
\end{tabular}

From Table 3, $\mathrm{R}_{1870-1970}$ and $\mathrm{R}_{\mathrm{C} 2250-2330}$ behaved the best among the raw and continuum removal types of spectral variables, respectively, with $R^{2}$ higher than $0.65(p<0.01)$, this mainly because the raw spectral reflectance at $1870-1970 \mathrm{~nm}$ and the continuum-removed reflectance at 2250-2330 $\mathrm{nm}$ achieved higher correlation with LWC, compared to the reflectance at the other spectral regions presented in the table (Figure 3 and Figure 4). As shown in Figure 6, two $\operatorname{DVI}_{C}$ indices $\left(\operatorname{DVI}_{C}(2280,1900)\right.$ and $\operatorname{DVI}_{C}(2280,1410)$ ) outperformed the $\mathrm{NDVI}_{\mathrm{C}}$ and $\mathrm{RVI}_{\mathrm{C}}$ types of indices with the corresponding spectral bands included. As expected, VIs with $1900 \mathrm{~nm}\left(\mathrm{VI}_{\mathrm{C}}(2280,1900)\right)$ yielded better results than those with $1410 \mathrm{~nm}\left(\mathrm{VI}_{\mathrm{C}}(2280,1410)\right), R^{2}$ of $\operatorname{DVI}_{\mathrm{C}}(2280,1900), \mathrm{NDVI}_{\mathrm{C}}(2280,1900)$ and $\operatorname{RVI}_{\mathrm{C}}(2280,1900)$ models were $0.72,0.58$ and 0.54 , improved by about $38.5 \%, 70.6 \%$ and $67.7 \%$, respectively, over their counterparts models $\left(R^{2}=0.52\right.$, 0.34 and 0.31 , respectively).

3.6.2 Model validation

Based on the results presented above, only models whose determination of coefficient higher than 0.65 were validated, i.e. $\mathrm{R}_{1870-1970}, \mathrm{R}_{\mathrm{C} 2250-2330}$ and $\mathrm{DVI}_{\mathrm{C}}(2280,1410)$. An independent dataset were used for the validation, the scattering plots between measured LWC and predicted LWC are presented in Figure 7. We can find that the $\operatorname{DVI}_{\mathrm{C}}(2280,1900)$ prediction had led to the highest $R^{2}$ value $\left(R^{2}=0.64\right)$ and the lowest RMSE and MAE values $(\mathrm{RMSE}=2.12, \mathrm{MAE}=1.75)$, indicating that it were the best model throughout all the spectral variables/indices tested in the study, to quantify the dynamic changes of LWC of soybean under different drought stresses. 


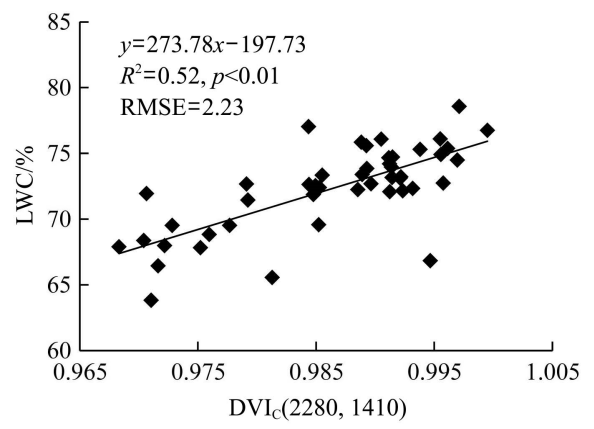

a.

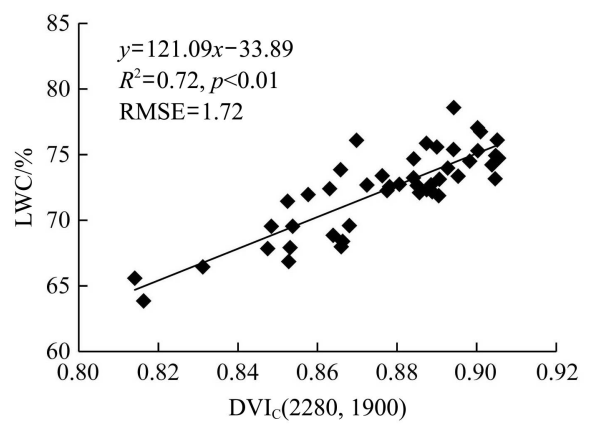

d.

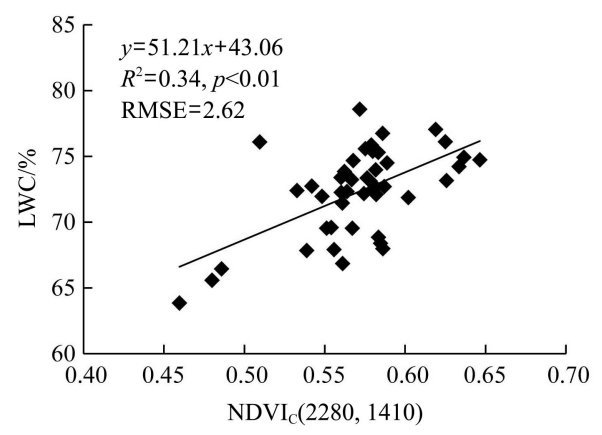

b.

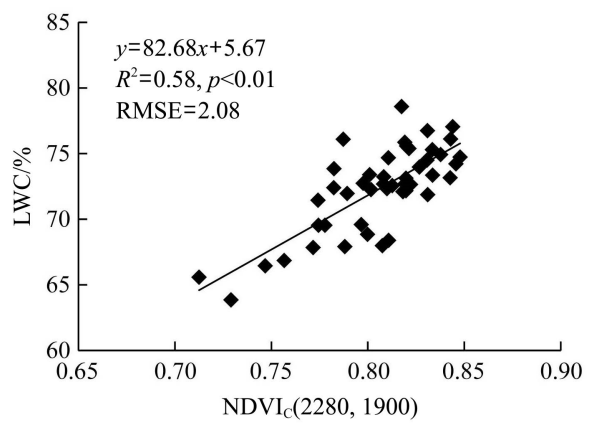

e.

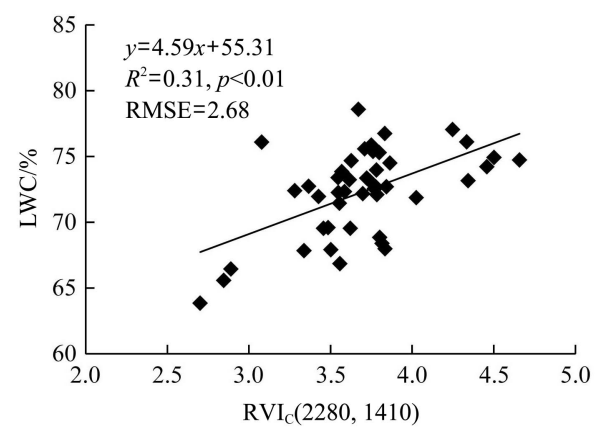

c.

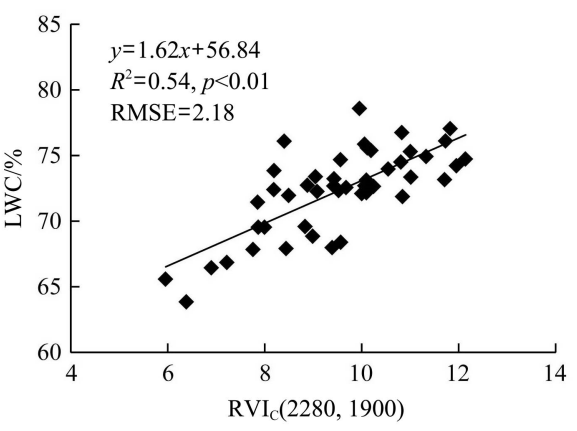

f.

Figure 6 Retrieval models between $\operatorname{LWC}$ vs. $\mathrm{VI}_{\mathrm{C}}(\lambda 1, \lambda 2)(n=46) . \quad \mathrm{VI}_{\mathrm{C}}$ includes $\mathrm{DVI}_{\mathrm{C}}$ (a) \& (d), $\mathrm{NDVI}_{\mathrm{C}}$ (b) \& (e) and $\mathrm{RVI}_{\mathrm{C}}(\mathrm{c}) \&(\mathrm{f})$
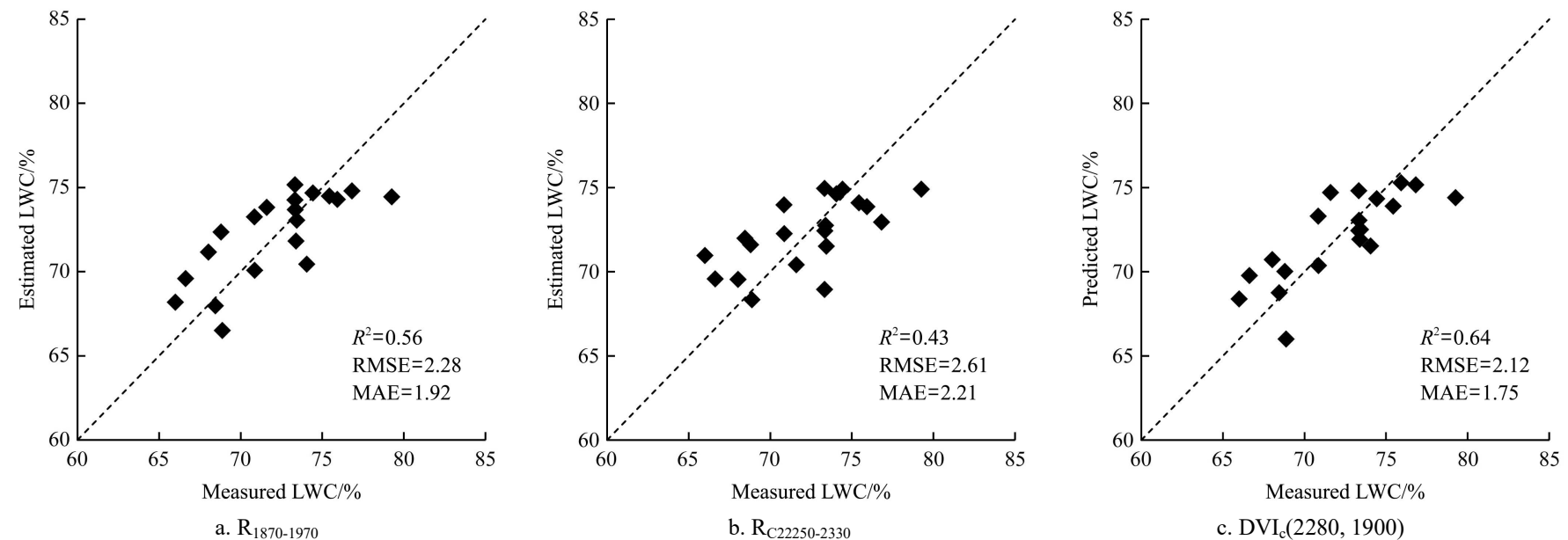

Figure 7 Scattering plots between measured LWC and predicted LWC $(n=20)$

\section{Conclusions}

Quantification of leaf water content (LWC) of crops, from hyperspectral remote sensing data, provides an avenue to evaluate the mycorrhizal effect on the growth of crops, especially at the arid and semi-arid regions. This study showed that the remote sensing technology hold a promising potential in estimating LWC of the inoculated and non-inoculated soybean under drought stresses. LWC of soybean obviously decreased after suffering from drought stress. However, under the same drought stress level, the leaves of inoculated soybean had higher LWC than that of non-inoculated counterparts at Day 45, indicating that arbuscular mycorrhizal inoculation contributes to resist the drought. Additionally, the spectral absorption features of water of the inoculated leaves at the near infrared and short-wave infrared regions were more significant than that of the non-inoculated leaves, resulting in lower spectral reflectance values, especially at $1900 \mathrm{~nm}$ and $1410 \mathrm{~nm}$. These absorption features were highlighted accordingly through the continuum removal processing. LWC had a high correlation with the reflectance of raw spectra at 1870-1970 nm and 1400-1460 nm, and the reflectance of continuum-removed spectra at 2250-2330 nm, $1850-1890 \mathrm{~nm}, 1690-1730 \mathrm{~nm}$ and $1125-1175 \mathrm{~nm}$, which can be regarded as the sensitive bands for remote estimation of LWC. The most robust index was $\operatorname{DVI}_{\mathrm{C}}(2280,1900)$, which was developed in this study as the best estimator of LWC for the inoculated and non-inoculated soybean. It integrates the information on the raw spectra at $1900 \mathrm{~nm}$ with the continuum-removed spectra at $2280 \mathrm{~nm}$ in the type of different vegetation index (DVI), leading to the most accurate estimation and prediction abilities over the other vegetation indices tested.

The LWC retrieval models proposed in this study were essential to the development of predictive algorithm that could not be efficiently designed, however, they were built based on the in situ spectral data. With the development of remote sensing technology, the high resolution hyperspectral imagery acquired from an unmanned aerial vehicle (UAV) is increasingly attracting researchers' attentions in the field of precision agriculture, more efforts should be taken to validate the retrieval models based on the UAV-based data at the field scale in the future. 


\section{Acknowledgements}

This work was supported by National Key Research and Development Program of China (2016YFB0501501), National Natural Science Foundation of China (41901369), the Strategic Priority Research Program of the Chinese Academy of Sciences (XDA13030402), and The Innovation Program of Academy of Opto-Electronics (AOE), Chinese Academy of Science (CAS) (Y70B16A15Y). The authors are grateful to the reviewers for their helpful comments. We also would like to thank all the colleagues contributing to the field campaign.

\section{[References]}

[1] Abdel-Salam E, Alatar A, El-Sheikh M A. Inoculation with arbuscular mycorrhizal fungi alleviates harmful effects of drought stress on damask rose. Saudi Journal of Biological Sciences, 2018; 25: 1772-1780.

[2] Zhao J, Chen C. Geography of China. Beijing: Higher Education Press, 2004.

[3] Smith S E, Read D. Mycorrhizal Symbiosis. Cambridge: Academic Press, 2008.

[4] Allen M F. Influence of vesicular-arbuscular mycorrhiza on water movement through buteloua gracilis lag ex steud. New Phytologist, 1982; 91: 191-196.

[5] Aliasgharzad N, Neyshabouri M R, Salimi G. Effects of arbuscular mycorrhizal fungi and bradyrhizobium japonicum on drought stress of soybean. Biologia, 2006; 61: S324-S328.

[6] Grumberg B C, Urcelay C, Shroeder M A, Vargas-Gil S, Luna C M. The role of inoculum identity in drought stress mitigation by arbuscular mycorrhizal fungi in soybean. Biology and Fertility of Soils, 2015; 51: $1-10$.

[7] Buschmann C. Structural and functional responses to environmental stresses: Water shortage. Journal of Plant Physiology, 1991; 137: 511.

[8] Clevers J, Kooistra L. Using hyperspectral remote sensing data for retrieving canopy chlorophyll and nitrogen content. IEEE Journal of Selected Topics in Applied Earth Observations and Remote Sensing, 2012; 5: 574-583.

[9] Kong W P, Huang W J, Zhou X F, Song X Y, Casa R Estimation of carotenoid content at the canopy scale using the carotenoid triangle ratio index from in situ and simulated hyperspectral data. Journal of Applied Remote Sensing, 2016; 10(2): 026035.

[10] Zhou X, Huang W, Kong W P, Ye H C, Luo J H, Chen P F. Remote estimation of canopy nitrogen content in winter wheat using airborne hyperspectral reflectance measurements. Adv. Space Res., 2016; 58: 1627-1637.

[11] Haboudane D, Miller J R, Pattey E, Zarco-Tejada P J, Strachan I B. Hyperspectral vegetation indices and novel algorithms for predicting green lai of crop canopies: Modeling and validation in the context of precision agriculture. Remote Sensing of Environment, 2004; 90: 337-352.

[12] Ahlrichs J S, Bauer M E. Relation of agronomic and multispectral reflectance characteristics of spring wheat canopies. Agron. J., 1983; 75: 987-993.

[13] Cao Z X, Wang Q, Zheng C L. Best hyperspectral indices for tracing leaf water status as determined from leaf dehydration experiments. Ecol. Indic., 2015; 54: 96-107.

[14] Zarco-Tejada P J, Rueda C A, Ustin S L. Water content estimation in vegetation with modis reflectance data and model inversion methods.
Remote Sensing of Environment, 2003; 85: 109-124.

[15] Sims D A, Gamon J A. Estimation of vegetation water content and photosynthetic tissue area from spectral reflectance: A comparison of indices based on liquid water and chlorophyll absorption features. Remote Sensing of Environment, 2003; 84: 526-537.

[16] Lars G, Sarita K-S, Timo K, Elina O, Markku K. Imaging lichen water content with visible to mid-wave infrared (400-5500 nm) spectroscopy. Remote Sensing of Environment, 2018; 216: 301-310.

[17] Penuelas J, Pinol J, Ogaya R, Filella I. Estimation of plant water concentration by the reflectance water index wi (r900/r970). International Journal of Remote Sensing, 1997; 18: 2869-2875.

[18] Gao B C. Ndwi - a normalized difference water index for remote sensing of vegetation liquid water from space. Remote Sensing Of Environment, 1996; 58: 257-266.

[19] Wang Q, Li P H. Identification of robust hyperspectral indices on forest leaf water content using prospect simulated dataset and field reflectance measurements. Hydrol. Process., 2012; 26: 1230-1241.

[20] Rasmussen C E, Nickisch H. Gaussian processes for machine learning (gpml) toolbox. Journal of Machine Learning Research, 2010; 11: 3011-3015.

[21] Campos-Taberner M, Garcia-Haro F J, Camps-Valls G, Grau-Muedra G, Nutini F, Crema A, et al. Multitemporal and multiresolution leaf area index retrieval for operational local rice crop monitoring. Remote Sensing of Environment, 2016; 187: 102-118.

[22] Upreti D, Huang W J, Kong W P, Pascucci S, Pignatti S, Zhou X F, et al A comparison of hybrid machine learning algorithms for the retrieval of wheat biophysical variables from sentinel-2. Remote Sens., 2019; 11(5): 481.

[23] Camps-Valls G, Verrelst J, Muñoz J, Laparra V, Mateo F, Gomez-Dans J. A survey on gaussian processes for earth-observation data analysis a comprehensive investigation. Ieee Geoscience And Remote Sensing Magazine, 2016; 4(2): 58-78.

[24] Clark R N, Roush T L. Reflectance spectroscopy- quantitative-analysis techniques for remote-sensing applications. Journal of Geophysical Research, 1984; 89: 6329-6340.

[25] Kokaly R F. Investigating a physical basis for spectroscopic estimates of leaf nitrogen concentration. Remote Sensing of Environment, 2001; 75: 153-161.

[26] Ortiz N, Armada E, Duque E, Roldán A, Azcón R. Contribution of arbuscular mycorrhizal fungi and/or bacteria to enhancing plant drought tolerance under natural soil conditions: Effectiveness of autochthonous or allochthonous strains. Journal of Plant Physiology, 2015; 174: 87-96.

[27] Danson F M, Steven M D, Malthus T J, Clark J A. High-spectral resolution data for determining leaf water content. International Journal of Remote Sensing, 1992; 13: 461-470.

[28] Ustin S L, Riano D, Hunt E R. Estimating canopy water content from spectroscopy. Israel Journal of Plant Sciences, 2012; 60: 9-23.

[29] Kokaly R F, Skidmore A K. Plant phenolics and absorption features in vegetation reflectance spectra near $1.66 \mu \mathrm{m}$. International Journal of Applied Earth Observation and Geoinformation, 2015; 43: 55-83.

[30] Rouse J W, Haas R H, Scheel J A, Deering D W. Monitoring vegetation systems in the great plains with erts. Proceedings, 3rd Earth Resource Technology Satellite (ERTS) Symposium, 1974; 1: 48-62.

[31] Liu S S, Peng Y, Du W, Le Y, Li L. Remote estimation of leaf and canopy water content in winter wheat with different vertical distribution of water-related properties. Remote Sens., 2015; 7: 4626-4650.

[32] Jordan C F. Derivation of leaf-area index from quality of light on forest floor. Ecology, 1969; 50: 663-666. 